\title{
Microwave Spectrum, Geometry, and Hyperfine Constants of PdCO
}

\author{
Nicholas R. Walker, ${ }^{\dagger}$ Joseph K-H. Hui, and Michael C. L. Gerry* \\ Department of Chemistry, The University of British Columbia, 2036 Main Mall, Vancouver, \\ British Columbia, Canada V6T 1Z1
}

Received: January 11, 2002; In Final Form: April 4, 2002

\begin{abstract}
The pure rotational spectrum of palladium monocarbonyl, PdCO, has been measured between 6000 and 24000 $\mathrm{MHz}$ using a cavity pulsed jet Fourier transform microwave spectrometer. The molecules were prepared by laser ablation of Pd in the presence of CO contained in an Ar backing gas. The spectra of 15 isotopomers have been used to determine the molecular geometry from the measured rotational constants. Centrifugal distortion constants are in good agreement with those calculated from a literature harmonic force field. A nuclear quadrupole coupling constant and nuclear spin-rotation constant have been determined for ${ }^{105} \mathrm{Pd}$. Nuclear shielding parameters have been evaluated from the measured spin-rotation constant. The geometry is discussed with reference to theoretical data and to other molecules containing an $\mathrm{M}-\mathrm{CO}$ bond.
\end{abstract}

\section{Introduction}

The group 10 elements, particularly $\mathrm{Pd}$ and $\mathrm{Pt}$, are catalysts for a diverse range of chemical reactions, with many of industrial significance. In the case of $\mathrm{Pd}$, this has been confirmed by a recent journal issue devoted entirely to this subject. ${ }^{1}$ The $\mathrm{CO}$ molecule is an ubiquitous ligand in inorganic chemistry. It is well-known as a "reversible poison" on Pd, enabling selectivity in catalytic hydrogenation reactions. ${ }^{2}$ The interactions within gas-phase $\mathrm{PdCO}$ are prototypes for those between a Pd surface and $\mathrm{CO}$, and consequently, the PdCO molecule has been the subject of many theoretical studies. ${ }^{3-15}$

The infrared spectrum of PdCO isolated in krypton was reported by Darling et al. ${ }^{16}$ in 1973 . Following this work, many groups have applied theoretical methods to examine aspects of the electronic structure of PdCO. All agree that it should have a linear ${ }^{1} \Sigma^{+}$ground state. Most recently, Manceron et al. ${ }^{3}$ and Liang et al. ${ }^{5}$ have used ab initio calculations in conjunction with matrix isolation experiments to provide estimates of the molecular geometries and binding energies of molecules of the form MCO (where $\mathrm{M}=\mathrm{Ni}, \mathrm{Pt}$, and Pd). Although many of the theoretical studies have predicted internuclear distances for $\mathrm{PdCO},{ }^{3-15}$ there is little agreement among them. The predicted PdC bond lengths, for example, vary from 1.81 to $2.21 \AA$. An experimental determination of the geometry has clearly been needed.

Evans et al. determined experimental geometries and bond lengths for molecules of the form ArMX (where $\mathrm{M}$ is $\mathrm{Cu}, \mathrm{Ag}$, and $\mathrm{Au}$ and $\mathrm{X}$ is $\mathrm{F}, \mathrm{Cl}$, and $\mathrm{Br})^{17-20}$ via Fourier transform microwave spectroscopy. It was shown that these species are comparatively rigid. In addition, the MX moieties undergo significant charge redistribution upon the attachment of argon. These observations are consistent with comparatively strong ArM bonds in the above species. Subsequent work has shown that molecules of the form OCMX can also be generated by laser ablation, and the structures and hyperfine constants of these

* To whom correspondence should be addressed. Phone: (604) 822 2464. Fax: +1-604-822-2847. E-mail: mgerry@chem.ubc.ca.

$\dagger$ Present address: Department of Chemistry, The University of Georgia, Athens, GA 30602, USA. species have also been accurately determined from the measured rotational constants. ${ }^{21-23}$ It is notable that these molecules possess $\mathrm{CO}$ distances that are comparable with those existing in free $\mathrm{CO}$. The MC distances are comparatively long; the AuC distance in OCAuX is shorter than the $\mathrm{AgC}$ distance in OCAgX because of relativistic effects. Very recently, the microwave spectrum of PtCO has been assigned, and accurate bond distances have been determined, ${ }^{24}$ along with centrifugal distortion constants and a nuclear spin-rotation term for ${ }^{195} \mathrm{Pt}$ in ${ }^{195} \mathrm{PtCO}$. Nuclear shielding parameters for ${ }^{195} \mathrm{Pt}$ were determined from the spin-rotation constant. It is significant that $\mathrm{Ni}(0), \mathrm{Pd}-$ $(0)$, and $\mathrm{Pt}(0)$ are isoelectronic with $\mathrm{Cu}(\mathrm{I}), \mathrm{Ag}(\mathrm{I})$, and $\mathrm{Au}(\mathrm{I})$, respectively.

This paper reports the detection and measurement of the microwave rotational spectrum of PdCO. This is the first gas phase study of the molecule, which has been found to be linear with a ${ }^{1} \Sigma^{+}$ground state, in agreement with the theoretical predictions. The spectra of several isotopomers have been studied, from which have been obtained rotational constants, centrifugal distortion constants, and, where appropriate, ${ }^{105} \mathrm{Pd}$ hyperfine constants. The PdC and $\mathrm{CO}$ bond lengths have been calculated by several methods. The results are discussed in comparison with those obtained for $\mathrm{PtCO}^{24}$ and other molecules containing a metal-carbonyl group bond.

\section{Experimental Methods}

Experiments were conducted using a laser ablation system in conjunction with a Balle-Flygare ${ }^{25}$ type Fourier transform microwave (FTMW) spectrometer. The system has been described at length in earlier papers, ${ }^{26-28}$ so only a brief description will be provided here. The microwave cavity comprises of two spherical aluminum mirrors $(28 \mathrm{~cm}$ diameter, radius of curvature $38.4 \mathrm{~cm}$ ) separated by approximately $30 \mathrm{~cm}$. One mirror is fixed, and the other is manually adjustable in order to permit the cavity to be tuned to the polarization frequency. The supersonic jet enters the cavity via a General Valve (Series 9) nozzle mounted slightly off-center in the fixed mirror. This arrangement optimizes the sensitivity and resolution of the spectrometer but causes all of the lines to be observed as Doppler pairs because 


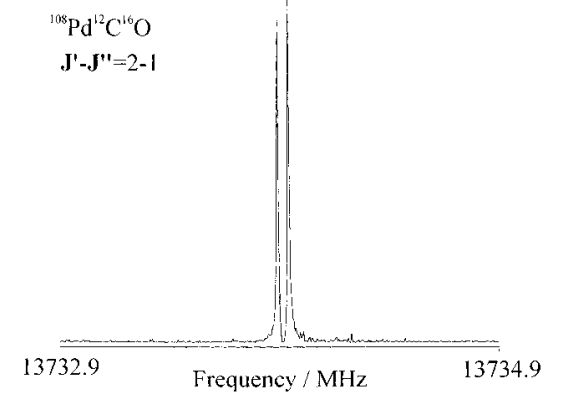

Figure 1. $J=2-1$ transition of ${ }^{108} \mathrm{Pd}^{12} \mathrm{C}^{16} \mathrm{O}$. Experimental conditions; $1 \% \mathrm{CO}$ in Ar, backing pressure 5-6 atm, 200 averaging cycles. Pd foil on glass rod used as ablation target. Radiation $(1064 \mathrm{~nm})$ from $\mathrm{Nd}$ :YAG used for ablation. $4 \mathrm{k}$ data points, $4 \mathrm{k}$ transform.

the direction of microwave propagation is parallel to the direction of the supersonic jet. The line position is determined by finding the average frequency of the two Doppler components. All measurements are referenced to a Loran $\mathrm{C}$ frequency standard that is accurate to 1 part in $10^{10}$.

The PdCO molecules were generated via the laser ablation $(\mathrm{Nd}: Y A G, 1064 \mathrm{~nm})$ of a palladium sample in the presence of a gas mixture containing carbon monoxide and argon. A thin sheet of Pd foil was wrapped around a glass rod and placed approximately $5 \mathrm{~mm}$ from the orifice of the pulsed nozzle in order to provide the ablation target. This was simultaneously rotated and translated in order to expose a fresh surface of metal prior to each laser shot. The gas mixture consisted of $0.5 \%-$ $1.5 \% \mathrm{CO}$ (Praxair) in an argon backing gas. The intensity of the observed spectral lines was found to be uniform over this concentration range. In order that experiments could be conducted on complexes containing ${ }^{18} \mathrm{O}$ and/or ${ }^{13} \mathrm{C}$ isotopes, isotopically enriched samples of ${ }^{13} \mathrm{CO}$ and $\mathrm{C}^{18} \mathrm{O}$ were employed.

\section{Assigned Spectra and Analysis}

The results of calculations by Liang et al. ${ }^{5}$ provided a preliminary estimate for the structure of PdCO. A rotational constant for the molecule was predicted from these data, and a search for lines in the microwave spectrum of the species was initiated. A line was identified at a frequency of $\sim 13685 \mathrm{MHz}$, $200 \mathrm{MHz}$ above the predicted position of the $J=2-1$ transition of ${ }^{108} \mathrm{PdCO}$. The transition of the isotopomer containing the heaviest isotope of $\mathrm{Pd}$ is expected at the lowest frequency. The frequency interval separating adjacent isotopomers of $\mathrm{Pd}$ of even mass was predicted to be of the order of $50 \mathrm{MHz}$, and no lines were observed within the $400 \mathrm{MHz}$ interval immediately below the position of this line. The line was therefore initially assigned to the ${ }^{110} \mathrm{PdCO}$ isotopomer.

A revised estimate of the structure of the molecule was made, and the rotational constants of isotopomers containing ${ }^{108} \mathrm{Pd}$, ${ }^{106} \mathrm{Pd}$, and ${ }^{104} \mathrm{Pd}$ were predicted. Transitions from these species were identified within $5 \mathrm{MHz}$ of the frequencies predicted from the revised rotational constants. Of the five isotopes of palladium, only ${ }^{105} \mathrm{Pd}$ has a nuclear spin. Because $I\left({ }^{105} \mathrm{Pd}\right)=5 / 2$, the transitions of ${ }^{105} \mathrm{PdCO}$ showed hyperfine structure arising from nuclear quadrupole coupling and nuclear spin-rotation coupling. No hyperfine structure attributable to ${ }^{13} \mathrm{C}$ was observed. In total, data were collected from three $J^{\prime}-J^{\prime \prime}$ transitions for 15 isotopomers. The abundances of the various isotopes of $\mathrm{Pd}$ that were investigated, ${ }^{104} \mathrm{Pd},{ }^{105} \mathrm{Pd},{ }^{106} \mathrm{Pd},{ }^{108} \mathrm{Pd}$, and ${ }^{110} \mathrm{Pd}$, are $11.1 \%, 22.3 \%, 27.3 \%, 26.5 \%$, and $11.7 \%$, respectively. An example line, the $J=2-1$ transition of ${ }^{108} \mathrm{Pd}^{12} \mathrm{C}^{16} \mathrm{O}$, is given in Figure 1.
The measured line positions were fit to a rotational Hamiltonian of the form shown below using Pickett's SPFIT ${ }^{29}$ spectral line fitting program:

$$
\mathbf{H}=\mathbf{H}_{\mathrm{rot}}+\mathbf{H}_{\text {quad }}+\mathbf{H}_{\text {nucl.spin }}
$$

where

$$
\begin{gathered}
\mathbf{H}_{\mathrm{rot}}=B_{0} \boldsymbol{J}^{2}-D_{\mathrm{J}} \boldsymbol{J}^{4} \\
\mathbf{H}_{\text {quad }}=\left(\mathbf{V}_{\mathrm{Pd}}^{(2)} \cdot \mathbf{Q}_{\mathrm{Pd}}^{(2)}\right) \\
\mathbf{H}_{\text {nucl.spin }}=C_{I(\mathrm{Pd})} \boldsymbol{I}_{\mathrm{Pd}} \cdot \boldsymbol{J}
\end{gathered}
$$

Rotational constants $\left(B_{0}\right)$ and centrifugal distortion constants $\left(D_{\mathrm{J}}\right)$ were fit for every isotopomer studied. Nuclear quadrupole coupling constants, $e Q q$, and spin-rotation constants $C_{\mathrm{I}}$ were also determined for species containing ${ }^{105} \mathrm{Pd}$. The coupling scheme adopted for ${ }^{105} \mathrm{PdCO},{ }^{105} \mathrm{Pd}^{13} \mathrm{CO}$, and ${ }^{105} \mathrm{PdC}^{18} \mathrm{O}$ was $\boldsymbol{J}+\boldsymbol{I}_{\mathrm{Pd}}=\boldsymbol{F}$. Lines from the spectra of vibrationally excited states were not observed during this work, despite an extensive search. All of the data were therefore obtained exclusively for the ground vibrational state. The measured transition frequencies and their quantum number assignments are given in Table 1. The derived spectroscopic constants are in Table 2.

\section{Structures of the Complexes}

A. Structural Calculations. Because data were only collected from the ground vibrational state, it was not possible to calculate an equilibrium $\left(r_{\mathrm{e}}\right)$ geometry. Several other methods were therefore employed to provide estimates of the molecular structure. These included a ground-state effective $\left(r_{0}\right)$ geometry, a fitted substitution $\left(r_{\mathrm{I} \epsilon}\right)$ geometry, two mass-dependent $\left(r_{\mathrm{m}}^{(1)}\right.$ and $\left.r_{\mathrm{m}}^{(2)}\right)$ geometries, and a ground-state average $\left(r_{\mathrm{z}}\right)$ geometry, from which was obtained an estimated $r_{\mathrm{e}}$ structure. In each case, a least-squares fit based on experimental moments of inertia from 15 isotopomers of $\mathrm{PdCO}$ was performed.

$i$. Ground-State Effective $\left(r_{0}\right)$ Structure. This method ignores vibrational contributions to the ground-state moments of inertia. ${ }^{30}$ The bond lengths were fit directly to the moments of inertia $I_{0}$ obtained from the rotational constants in Table 2 using $^{30} I_{0}=h / 8 \pi^{2} B_{0}$ :

$$
I_{0}=I_{\text {rigid }}\left(r_{0}\right)
$$

These bond lengths are designated $r_{0}$, and $I_{\text {rigid }}\left(r_{0}\right)$ is calculated using rigid molecule formulas. The structure determined is provided in Table 3.

ii. Fitted Substitution $\left(r_{I \epsilon}\right)$ Structure. The contribution of vibrational effects to the measured moments of inertia is partially accounted for by the inclusion of a vibration-rotation parameter $(\epsilon)$, which is taken to be independent of isotopomer: ${ }^{31}$

$$
I_{0}=I_{\text {rigid }}\left(r_{\mathrm{I} \epsilon}\right)+\epsilon
$$

The same assumption is made in the conventional substitution method $\left(r_{\mathrm{s}}\right),{ }^{32}$ and where principal moments of several isotopic species have been obtained (as in $\mathrm{PdCO}$ ), the resulting structures should be the same. Such a fit was carried out, and the resulting $r_{\text {I } \epsilon}$ geometry is also in Table 3.

iii. Mass Dependent $\left(r_{m}^{(1)}\right.$ and $\left.r_{m}^{(2)}\right)$ Geometries. These geometries attempt to account for the mass dependence of $\epsilon$ and should produce near-equilibrium parameters from ground-state 
TABLE 1: Measured Rotational Transition Frequencies (in MHz) of PdCO

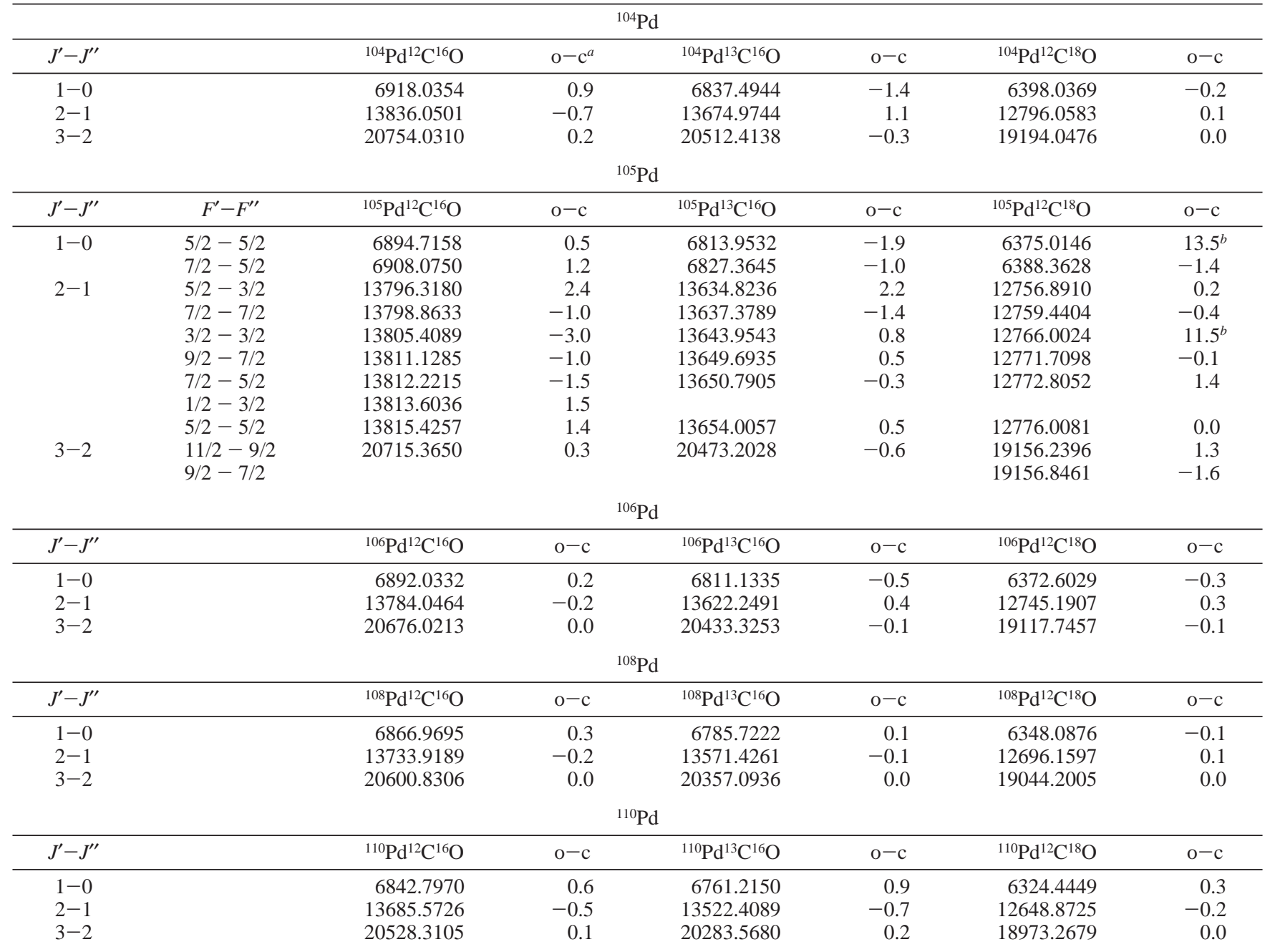

${ }^{a}$ Differences (in kHz) between observed frequencies and frequencies calculated using the derived constants in Table 2. ${ }^{b}$ Line excluded from fit.

moments of inertia. For a linear triatomic molecule, they are obtained using the expression ${ }^{33}$

$$
I_{0}=I_{\mathrm{m}}\left(r_{\mathrm{m}}\right)+c I_{\mathrm{m}}^{1 / 2}+d\left[\left(m_{1} m_{2} m_{3}\right) / M\right]^{1 / 4}
$$

where $r_{\mathrm{m}}$ are the derived bond lengths, $I_{\mathrm{m}}\left(r_{\mathrm{m}}\right)$ is $I_{\text {rigid }}$ using the $r_{\mathrm{m}}$ bond lengths, $c$ and $d$ are constants, $m_{1}, m_{2}$, and $m_{3}$ are atomic masses, and $M$ is the molecular mass. In an $r_{\mathrm{m}}^{(1)}$ fit, $d$ is set to zero; in an $r_{\mathrm{m}}^{(2)}$ fit, both $c$ and $d$ are included as fit parameters. Again, the results are in Table 3.

The $r_{\mathrm{m}}^{(1)}$ structure is fit to a single constant in addition to the moments of inertia, and the geometry thus has similar precision to the $r_{\mathrm{I} \epsilon}$ structure. $r_{\mathrm{m}}^{(2)}$ structures are in principle better approximations to $r_{\mathrm{e}}$ structures. However, where the molecule contains no atom near the center of mass (as in the present case), parameters may be subject to large uncertainties and correlations. ${ }^{33}$ In the present study, the $r_{\mathrm{m}}^{(2)}$ bond lengths are greater than the $r_{0}, r_{\mathrm{I} \epsilon}$, and $r_{\mathrm{m}}^{(1)}$ distances. This is unexpected in a diatomic approximation, which can be used as a rough guide. It is thus conceivable that the $r_{\mathrm{m}}^{(2)}$ distances in Table 3 are not good approximations to the $r_{\mathrm{e}}$ distances. The $r_{\mathrm{m}}^{(1)}$ structure contains significantly shorter bonds and is in good agreement with the calculated $r_{\mathrm{I} \epsilon}$ structure. It is believed to be closer to the $r_{\mathrm{e}}$ configuration than the $r_{\mathrm{m}}^{(2)}$ structure.

iv. Ground-State Average $\left(r_{z}\right)$ and Estimated Equilibrium $\left(r_{e}\right)$ Geometries. An $r_{\mathrm{z}}$ geometry was calculated for ${ }^{105} \mathrm{Pd}^{12} \mathrm{C}^{16} \mathrm{O}$.
Because the harmonic force field of ref 7 reproduced the distortion constants well (see Table 2), it was used to estimate the harmonic contributions to the $\alpha$ constants. These in turn were used to convert the experimental $B_{0}$ values to groundstate average $\left(B_{\mathrm{z}}\right)$ rotational constants. The $r_{\mathrm{z}}$ geometry was determined by fitting to the $B_{\mathrm{z}}$ constants by least squares. Isotopic variations in the bond lengths were accounted for using 34,35

$$
\delta r_{\mathrm{z}}=\frac{3}{2} a \delta\left\langle u^{2}\right\rangle-\delta K
$$

The required zero-point mean square amplitudes, $\left\langle u^{2}\right\rangle$, of the bonds and their perpendicular amplitude corrections, $K$, were obtained from the force field. The Morse parameter, $a$, for $\mathrm{CO}$ was obtained from tabulated values. ${ }^{36}$ That of PdC was estimated from the force constant $k$ in ref 7 and the dissociation energy in ref 3 , using $k=2 D_{\mathrm{e}} a^{2}$; the value used was $2.2 \AA^{-1}$. The resulting $r_{\mathrm{z}}$ values are in Table 3; the uncertainties given arise from the least-squares fit. An equilibrium geometry was also estimated from the $r_{\mathrm{z}}$ structure, using 34,35

$$
r_{\mathrm{e}}=r_{\mathrm{z}}-\frac{3}{2} a\left\langle u^{2}\right\rangle+K
$$

This, too, is given in Table 3. Although the uncertainties in the desired $r_{\mathrm{e}}$ distances are difficult to estimate, they are probably 
TABLE 2: Derived Spectroscopic Constants (in MHz) of PdCO

\begin{tabular}{|c|c|c|c|c|c|c|}
\hline \multicolumn{7}{|c|}{${ }^{104} \mathrm{Pd}$} \\
\hline parameter & ${ }^{104} \mathrm{Pd}^{12} \mathrm{C}^{16} \mathrm{O}$ & $\mathrm{calc}^{a}$ & ${ }^{104} \mathrm{Pd}^{13} \mathrm{C}^{16} \mathrm{O}$ & calc & ${ }^{104} \mathrm{Pd}^{12} \mathrm{C}^{18} \mathrm{O}$ & calc \\
\hline$B_{0}$ & $3459.01878(36)^{b}$ & & $3418.74943(36)$ & & $3199.01983(36)$ & \\
\hline$D_{\mathrm{J}} \times 10^{3}$ & $0.7579(241)$ & 0.79 & $0.7643(241)$ & 0.78 & $0.6611(241)$ & 0.66 \\
\hline \multicolumn{7}{|c|}{${ }^{105} \mathrm{Pd}$} \\
\hline parameter & ${ }^{105} \mathrm{Pd}^{12} \mathrm{C}^{16} \mathrm{O}$ & calc & ${ }^{105} \mathrm{Pd}^{13} \mathrm{C}^{16} \mathrm{O}$ & calc & ${ }^{105} \mathrm{Pd}^{12} \mathrm{C}^{18} \mathrm{O}$ & calc \\
\hline$B_{0}$ & $3452.448635(211)$ & & $3412.088443(217)$ & & $3192.593236(216)$ & \\
\hline$D_{\mathrm{J}} \times 10^{3}$ & $0.7264(190)$ & 0.79 & $0.7518(190)$ & 0.78 & $0.6685(160)$ & 0.66 \\
\hline$e Q q(\mathrm{Pd})$ & $63.6653(31)$ & & $63.1467(35)$ & & $63.6912(37)$ & \\
\hline$C_{\mathrm{I}}(\mathrm{Pd}) \times 10^{3}$ & $-2.914(157)$ & & $-3.041(195)$ & & $-3.159(213)$ & \\
\hline \multicolumn{7}{|c|}{${ }^{106} \mathrm{Pd}$} \\
\hline parameter & ${ }^{106} \mathrm{Pd}^{12} \mathrm{C}^{16} \mathrm{O}$ & calc & ${ }^{106} \mathrm{Pd}^{13} \mathrm{C}^{16} \mathrm{O}$ & calc & ${ }^{106} \mathrm{Pd}^{12} \mathrm{C}^{18} \mathrm{O}$ & calc \\
\hline$B_{0}$ & $3446.01811(36)$ & & $3405.56854(36)$ & & $3186.30291(36)$ & \\
\hline$D_{\mathrm{J}} \times 10^{3}$ & $0.8097(241)$ & 0.79 & $0.7951(241)$ & 0.78 & $0.6642(241)$ & 0.66 \\
\hline \multicolumn{7}{|c|}{${ }^{108} \mathrm{Pd}$} \\
\hline parameter & ${ }^{108} \mathrm{Pd}^{12} \mathrm{C}^{16} \mathrm{O}$ & calc & ${ }^{108} \mathrm{Pd}^{13} \mathrm{C}^{16} \mathrm{O}$ & calc & ${ }^{108} \mathrm{Pd}^{12} \mathrm{C}^{18} \mathrm{O}$ & calc \\
\hline$B_{0}$ & $3433.48621(36)$ & & $3392.86261(36)$ & & $3174.04512(36)$ & \\
\hline$D_{\mathrm{J}} \times 10^{3}$ & $0.8033(241)$ & 0.78 & $0.7600(241)$ & 0.77 & $0.6507(241)$ & 0.66 \\
\hline \multicolumn{7}{|c|}{${ }^{110} \mathrm{Pd}$} \\
\hline parameter & ${ }^{110} \mathrm{Pd}^{12} \mathrm{C}^{16} \mathrm{O}$ & calc & ${ }^{110} \mathrm{Pd}^{13} \mathrm{C}^{16} \mathrm{O}$ & calc & ${ }^{110} \mathrm{Pd}^{12} \mathrm{C}^{18} \mathrm{O}$ & calc \\
\hline$B_{0}$ & $3421.39982(36)$ & & $3380.60862(36)$ & & $3162.22367(36)$ & \\
\hline$D_{\mathrm{J}} \times 10^{3}$ & $0.8199(241)$ & 0.78 & $0.7769(241)$ & 0.77 & $0.6864(241)$ & 0.65 \\
\hline
\end{tabular}

${ }^{a}$ Distortion constants calculated from the force field of Tremblay et al. ${ }^{7}{ }^{b}$ Numbers in parentheses are one standard deviation in units of the last significant figure.

TABLE 3: Bond Lengths (in $\AA$ ) Determined for PdCO, in Comparison with Earlier ab Initio Values

\begin{tabular}{|c|c|c|c|}
\hline & method & $r(\mathrm{PdC})$ & $r(\mathrm{CO})$ \\
\hline \multirow[t]{29}{*}{$\mathrm{PdCO}$} & $r_{0}$ (this work) & $1.8447(1)$ & $1.1374(2)$ \\
\hline & $r_{\mathrm{I} \epsilon}($ this work $)$ & $1.8438(2)$ & $1.1380(2)\left(\epsilon=0.06\right.$ a.m.u. $\left.\AA^{2}\right)$ \\
\hline & $r_{\mathrm{m}}^{(1)}$ (this work) & $1.8434(3)$ & $1.1378(1)\left(c=0.01\right.$ a.m.u. $\left.{ }^{1 / 2} \AA\right)$ \\
\hline & $r_{\mathrm{m}}^{(2)}($ this work $)$ & $1.84127(4)$ & $\begin{array}{c}1.14034(4)\left(c=-0.024 \text { a.m.u. }{ }^{1 / 2} \AA\right. \\
\left.d=0.13 \text { a.m.u. }{ }^{1 / 2} \AA^{2}\right)\end{array}$ \\
\hline & $r_{\mathrm{z}}$ (this work) & $1.8454(2)$ & $1.1370(2)$ \\
\hline & $r_{\mathrm{e}}$ (this work) & $1.8401(2)$ & $1.1360(2)$ \\
\hline & DFT $^{\mathrm{a}}$ & 1.900 & 1.174 \\
\hline & $\mathrm{DFT}^{\mathrm{b}}$ & 1.873 & 1.143 \\
\hline & MP2/LANL2DZ ${ }^{c}$ & 1.833 & 1.153 \\
\hline & $X \alpha(\mathrm{N} \text { Rel })^{d}$ & 1.87 & 1.15 \\
\hline & $X \alpha(\mathrm{rel})^{d}$ & 1.81 & 1.15 \\
\hline & $\mathrm{GC}(\mathrm{N} \text { Rel })^{d}$ & 1.86 & 1.16 \\
\hline & ${\mathrm{LDA} / \mathrm{LDA}^{e}}$ & 1.814 & 1.157 \\
\hline & $\mathrm{NLC} / L D A^{e}$ & 1.863 & 1.157 \\
\hline & $\mathrm{NLC} / \mathrm{NLC}^{e}$ & 1.917 & 1.166 \\
\hline & $\mathrm{HF}^{f}$ & 2.211 & 1.107 \\
\hline & MP2 $f$ & 1.909 & 1.153 \\
\hline & MP3 $f$ & 1.996 & 1.132 \\
\hline & CISD $^{f}$ & 1.993 & 1.127 \\
\hline & CISC $^{f}$ & 1.965 & 1.139 \\
\hline & GVBPP $^{g}$ & 1.96 & 1.14 \\
\hline & $\mathrm{SCF}^{h}$ & 2.01 & 1.159 \\
\hline & $\mathrm{CASSCF}^{h}$ & 1.90 & 1.159 \\
\hline & MRCCI1 $2^{h}$ & 1.868 & 1.159 \\
\hline & $\mathrm{CPF} 20^{h}$ & 1.863 & 1.159 \\
\hline & $\mathrm{SCF}^{h}$ & 1.863 & 1.159 \\
\hline & $\mathrm{CI}^{i}$ & 2.106 & 1.159 \\
\hline & $\mathrm{SCF}^{j}$ & 2.056 & 1.130 \\
\hline & $\mathrm{MP}^{j}$ & 1.882 & 1.185 \\
\hline
\end{tabular}

${ }^{a}$ Reference 15. ${ }^{b}$ Reference 5. ${ }^{c}$ Reference $3 .{ }^{d}$ Reference $6 .{ }^{e}$ Reference 12. ${ }^{f}$ Reference $11 .{ }^{g}$ Reference $10 .{ }^{h}$ Reference $9\left(r_{\mathrm{CO}}\right.$ fixed at $1.159 \AA$ A). ${ }^{i}$ Reference $8 .{ }^{j}$ Reference 4 .

close to those of the $r_{\mathrm{z}}$ values. It is interesting that, although the estimated $r_{\mathrm{e}}$ value of $\mathrm{PdC}$ is fairly close to the $r_{\mathrm{m}}^{(2)}$ value, this is not the case for $r_{\mathrm{e}}(\mathrm{CO})$. In keeping with the suggestion above, the estimated $r_{\mathrm{e}}$ values agree better overall with the $r_{\mathrm{m}}^{(1)}$ values. For the purpose of comparing the bond lengths with those derived from ab initio calculations, the values $r(\mathrm{PdC})=$ $1.843(3) \AA$ and $r(\mathrm{CO})=1.138(2) \AA$ would probably be the most useful.

B. Discussion of the Structure. The derived bond lengths of PdCO are also compared in Table 3 with a large selection of the $a b$ initio values obtained over the past 20 years. The latter are arranged in reverse chronological order; it is reassuring to note the significant degree of convergence of these values in recent years. The values of Manceron et al., ${ }^{3}$ Liang et al., ${ }^{5}$ and Cheung et al. ${ }^{6}$ give reasonable, if imperfect, agreement with experiment. The experimental PdC distance has been found to approximate the average of the results of the nonrelativistic and relativistic $\mathrm{X} \alpha$ calculations performed by Cheung et al. The method employed by Manceron et al. provides a particularly good estimate of $r(\mathrm{PdC})$; the $\mathrm{CO}$ distance is overestimated by $\sim 0.015 \AA$. The result of Durà-Vilà et al. ${ }^{15}$ is less accurate than those of the other recent studies; the calculated $\mathrm{CO}$ distance is larger than the experimental value by $\sim 0.03 \AA$ and the $\mathrm{PdC}$ distance is larger by $\sim 0.06 \AA$. It should be noted however, that this group selected a functional and basis functions that are more appropriate to the treatment of larger clusters. The earlier calculations have given geometries of varying, often poor, agreement with experiment.

Table 4 contains a comparison of the geometry of $\mathrm{PdCO}$ with those of a variety of other simple carbonyls. There are several notable features. In the first place, $r(\mathrm{PdC})$ is much larger than $r(\mathrm{PtC})$ in $\mathrm{PtCO}$. This was predicted ${ }^{6,13}$ and is the result of relativistic effects on $\mathrm{Pt}$ in $\mathrm{PtCO}$. A parallel phenomenon occurs in $\mathrm{OCAgX}$ and $\mathrm{OCAuX}(\mathrm{X}=\mathrm{F}, \mathrm{Cl}$, and $\mathrm{Br})$, where $r(\mathrm{AgC})>$ $r(\mathrm{AuC})$, this time because of relativistic effects on $\mathrm{Au}$ in OCAuX. ${ }^{22,23}$ Second, whereas in the coinage metal (group 11) carbonyl halides the $r(\mathrm{CO})$ values are close to that of free $\mathrm{CO}$ $(1.128 \AA)$, the corresponding values for $\mathrm{PdCO}$ and $\mathrm{PtCO}$ are 
TABLE 4: Comparison of Bond Lengths of PdCO (in $\AA$ ) with Those of Related Molecules

\begin{tabular}{lccl}
\hline & $r(\mathrm{MC})$ & $r(\mathrm{CO})$ & \multicolumn{1}{c}{ comments } \\
\hline $\mathrm{OCCuF}$ & 1.765 & 1.131 & $r_{\mathrm{I} \epsilon}$ values, (FTMW, ref 21) \\
OCCuCl & 1.795 & 1.129 & $r_{\mathrm{I} \epsilon}$ values, (FTMW, ref 21) \\
$\mathrm{OCCuBr}$ & 1.803 & 1.128 & $r_{\mathrm{I} \epsilon}$ Values, (FTMW, ref 21) \\
OCAgF & 1.965 & 1.126 & $r_{\mathrm{I} \epsilon}$ values, (FTMW, ref 23) \\
$\mathrm{OCAgCl}$ & 2.013 & 1.124 & $r_{\mathrm{I} \epsilon}$ values, (FTMW, ref 23) \\
$\mathrm{OCAgBr}$ & 2.028 & 1.124 & $r_{\mathrm{I} \epsilon}$ values, (FTMW, ref 23) \\
$\mathrm{OCAuF}$ & 1.847 & 1.134 & $r_{0}$ values (FTMW, ref 22) \\
OCAuCl & 1.883 & 1.132 & $r_{\mathrm{I} \epsilon}$ values (FTMW, ref 22) \\
$\mathrm{OCAuBr}$ & 1.892 & 1.132 & $r_{\mathrm{I} \epsilon}$ Values (FTMW, ref 22) \\
$\mathrm{PtCO}$ & 1.760 & 1.148 & $r_{\mathrm{I} \epsilon}$ values, ref 24 \\
$\mathrm{PdCO}$ & 1.844 & 1.138 & $r_{\mathrm{I \epsilon}}$ values, this work \\
$\mathrm{NiCO}$ & 1.687 & 1.166 & CCSD, ref 44 \\
$\mathrm{FeCO}$ & 1.727 & 1.160 & $r_{\mathrm{I \epsilon}}$ Value, ref 45 \\
$\mathrm{Ni}(\mathrm{CO})_{4}$ & 1.838 & 1.141 & electron diffraction, ref 46 \\
$\mathrm{Fe}(\mathrm{CO})_{5}$ & 1.833 & 1.145 & electron diffraction, ref 47 \\
$\mathrm{CO}$ & & 1.128 & $r_{\mathrm{e}}$ value, ref 48
\end{tabular}

${ }^{a}$ The $r_{\mathrm{I} \epsilon}$ values are given in order to allow comparison with the bond lengths of OC-AuX. The preferred $r_{\mathrm{m}}^{(1)}$ values (Table 3) are within $0.0005 \AA$ of the $r_{\mathrm{I} \epsilon}$ values.

significantly greater. Correspondingly, $r(\mathrm{PdC})$ and $r(\mathrm{PtC})$ are significantly less than $r(\mathrm{AgC})$ and $r(\mathrm{AuC})$, respectively. The bonding in the group 10 monocarbonyls, unlike that of the coinage metal carbonyl halides, apparently conforms to the conventional picture of transition metal carbonyl bonding.

Finally, the $\mathrm{PdC}, \mathrm{PtC}$, and $\mathrm{CO}$ bond lengths are radically different from those of other Pd and Pt carbonyls. Very recently, Willner et al. ${ }^{37}$ reported the preparation and X-ray structural determination of the homoleptic cations $\mathrm{Pd}(\mathrm{CO})_{4}{ }^{2+}$ and $\mathrm{Pt}$ $(\mathrm{CO})_{4}{ }^{2+}$. In these ions, the metal-carbon distances have both been found to be 1.98-1.99 $\AA$, much larger than those of the monocarbonyls, and with essentially no metal dependence. The corresponding CO distances are $\sim 1.1 \AA$, much shorter than that of free CO. Similar values have been found for other $\mathrm{Pt}(\mathrm{CO})_{n}$ and $\mathrm{Pd}(\mathrm{CO})_{n}$ derivatives. ${ }^{37}$ Although it is difficult to rationalize completely the differences between the two sets of results, it should be noted that ref 37 also gives considerably longer ab initio $\mathrm{CO}$ distances. It should also be noted that an X-ray diffraction study of $\mathrm{OCAuCl}^{38}$ gave $r(\mathrm{AuC})=1.93 \AA$ and $r(\mathrm{CO})$ $=1.11 \AA$, which are significantly different from the microwave values. ${ }^{22}$ The latter, being produced for isolated molecules in a single state, are probably easier to rationalize physically.

\section{Vibrational Wavenumbers}

The distortion constant of a molecule is intimately related to its vibrational frequencies. From the measured vibrational frequencies, Manceron et al. ${ }^{7}$ were able to provide a harmonic force field for PdCO. This field has been used to estimate the distortion constants of various isotopomers of PdCO; the results are compared with experimental data in Table 2. It can be seen that good agreement exists in all cases, with typical differences $\sim 0.02 \mathrm{kHz}$ and the maximum difference $\sim 0.06 \mathrm{kHz}$.

An alternative approach involves direct calculation of the $\mathrm{PdC}$ stretching frequency from the measured distortion constant of a given isotopomer. A diatomic approximation is employed: ${ }^{39}$

$$
\omega \approx\left(\frac{4 B_{0}^{3}}{D_{\mathrm{J}}}\right)^{1 / 2}
$$

For the most abundant isotopomer, ${ }^{106} \mathrm{Pd}^{12} \mathrm{C}^{16} \mathrm{O}$, a value of 474 $\mathrm{cm}^{-1}$ is obtained. This is somewhat different from the experimental measurement of $615.7 \mathrm{~cm}^{-1}$. $^{7}$

\section{Hyperfine Coupling}

A. Nuclear Quadrupole Coupling Constant of ${ }^{105} \mathbf{P d}$. Although the ${ }^{105} \mathrm{Pd}$ nuclear quadrupole coupling constants are $\sim 64 \mathrm{MHz}$, these values are actually relatively small, given the large ${ }^{105} \mathrm{Pd}$ quadrupole moment. The latter is $66 \mathrm{fm}^{2}$, comparable in magnitude to that of ${ }^{127} \mathrm{I}\left(-78.9 \mathrm{fm}^{2}\right) .{ }^{40}$ Values of ${ }^{127} \mathrm{I}$ coupling constants $\sim 1000-2000 \mathrm{MHz}$ are common for covalently bonded iodine. ${ }^{30}$

The small ${ }^{105} \mathrm{Pd}$ coupling constants should not be a major surprise, however. The ground-state electron configuration of atomic $\mathrm{Pd}$ is $[\mathrm{Kr}] 4 \mathrm{~d}^{10}$, making the atom spherically symmetric. An electron pair donated from $\mathrm{CO}$ should go primarily into the Pd 5s orbital, which is also spherically symmetric. The small coupling constants would then arise from minor distortions of the spherical symmetry, presumably from $\pi$-back-donation of electron density from the $5 \mathrm{~d}$ orbitals on Pd to $\pi^{*}$ antibonding orbitals on $\mathrm{CO}$.

B. ${ }^{105}$ Pd Nuclear Shielding. Nuclear magnetic resonance (NMR) shielding constants can be calculated from the nuclear spin-rotation constants determined through microwave spectroscopy. ${ }^{41}$ Studies of this kind are useful because molecules may be studied in the absence of the solvent or lattice effects present in bulk materials. In addition, they permit the study of transient molecules and species with a large quadrupole interaction, which might otherwise be unsuitable for study by NMR spectroscopy, and provide valuable benchmarks for theoretical calculation. In microwave spectroscopy, the shieldings are determined directly, and there is no need to make comparisons with a standard.

The average shielding, $\sigma$, of ${ }^{105} \mathrm{Pd}$ in ${ }^{105} \mathrm{Pd}^{12} \mathrm{C}^{16} \mathrm{O}$ has been determined from the nuclear spin-rotation constant, $C_{\mathrm{I}}$, measured during this work. $C_{\mathrm{I}}$ can be expressed as a sum of nuclear and electronic contributions: ${ }^{41}$

$$
C_{\mathrm{I}}=C_{\mathrm{I}}(\text { nuc })+C_{\mathrm{I}}(\text { elec })
$$

The nuclear part depends on the nuclear positions and is given for a linear molecule by

$$
C_{\mathrm{I}}(\text { nuc })=-\left(\frac{2 e \mu_{\mathrm{N}} g_{\mathrm{N}} B}{h c}\right) \sum_{i \neq A}\left(\frac{Z_{i}}{r_{A i}}\right)
$$

where $e$ is the proton charge, $\mu_{\mathrm{N}}$ is the nuclear magneton, $g_{\mathrm{N}}$ is the $\mathrm{g}$ factor for the nucleus in question, $A\left(={ }^{105} \mathrm{Pd}\right.$ in this case), $B$ is the rotational constant, $Z_{i}$ is the atomic number of nucleus $i \neq A$, and $r_{A i}$ is the distance from nucleus $A$ to nucleus $i$. This yields $C_{\mathrm{I}}$ (nuc) $=0.081 \mathrm{kHz}$ and $C_{\mathrm{I}}($ elec $)=C_{\mathrm{I}}-C_{\mathrm{I}}($ nuc $)$, so $C_{\mathrm{I}}(\mathrm{elec})$ is $-2.995 \mathrm{kHz}$.

The shielding can also be written as a sum of two contributions:

$$
\sigma=\sigma_{\mathrm{p}}+\sigma_{\mathrm{d}}
$$

where $\sigma_{\mathrm{p}}$ and $\sigma_{\mathrm{d}}$ are the paramagnetic and diamagnetic parts, respectively. The paramagnetic part is proportional to $C_{\mathrm{I}}(\mathrm{elec})$

$$
\begin{aligned}
\sigma_{\mathrm{p}} & =-\left(\frac{e \hbar}{6 m c \mu_{\mathrm{N}} g_{\mathrm{N}} B}\right) C_{\mathrm{I}}(\text { elec }) \\
& =-\left(\frac{m_{\mathrm{p}}}{3 m g_{\mathrm{N}} B}\right) C_{\mathrm{I}}(\text { elec })
\end{aligned}
$$

$m$ and $m_{\mathrm{p}}$ are the masses of the electron and proton, respectively. From recent values of the fundamental constants, ${ }^{40}$ if $C_{\mathrm{I}}$ is in 
$\mathrm{kHz}$ and $B$ is in $\mathrm{MHz}$, then

$$
\sigma_{\mathrm{p}}=-612050.90(58)\left(\frac{C_{\mathrm{I}}(\mathrm{elec})}{g_{\mathrm{N}} B}\right)
$$

This gives $\sigma_{\mathrm{p}}=-2067 \mathrm{ppm}$ for ${ }^{105} \mathrm{Pd}$ in ${ }^{105} \mathrm{Pd}^{12} \mathrm{C}^{16} \mathrm{O}$. The diamagnetic part is calculated from

$$
\sigma_{\mathrm{d}}=\sigma_{\mathrm{d}}(\text { atom })-\left(\frac{m_{\mathrm{p}}}{3 m g_{\mathrm{N}} B}\right) C_{\mathrm{I}}(\text { nuc })
$$

in which $\sigma_{\mathrm{d}}($ atom) is the free atom diamagnetic shielding. The tables of Malli et al. ${ }^{42}$ list this quantity as $4511.42 \mathrm{ppm}$ for ${ }^{105} \mathrm{Pd}$. A value of $4567 \mathrm{ppm}$ is thus obtained for $\sigma_{\mathrm{d}}$, yielding a value of $2500 \mathrm{ppm}$ for $\sigma$.

The span $\Omega$ is defined by $\Omega=\sigma_{\|}-\sigma_{\perp}$, where $\sigma_{\|}$and $\sigma_{\perp}$ are the components of the shielding tensor parallel and perpendicular to the molecular axis, respectively. It can be estimated directly from the experimental values for $C_{\mathrm{I}}$ using ${ }^{43}$

$$
\Omega=\left(\frac{m_{\mathrm{p}}}{2 m g_{\mathrm{N}} B}\right) C_{\mathrm{I}}
$$

This yields a value of $3017(160)$ ppm for ${ }^{105} \mathrm{Pd}$ in ${ }^{105} \mathrm{Pd}^{12} \mathrm{C}^{16} \mathrm{O}$. This is large and comparable in magnitude to $\sigma$ itself. The ${ }^{105} \mathrm{Pd}$ shielding tensor, like that of ${ }^{195} \mathrm{Pt}$ in $\mathrm{PtCO},{ }^{24}$ is evidently very asymmetric.

\section{Conclusions}

PdCO has been generated by laser ablation and stabilized within a supersonic expansion. FTMW spectroscopy has been used to observe the microwave spectrum of the molecule, and its geometry has been precisely determined from the measured rotational constants of 15 isotopomers. These provide an important benchmark for future theoretical calculations of the molecular geometry and have permitted the accuracy of previous such calculations to be assessed. This is an important and much needed result, because none of the earlier calculations have predicted the complete experimental geometry to a high degree of accuracy. In contrast to the carbonyl halides of the coinage metals, OCMX, both PdCO and PtCO have been found to conform with a conventional transition metal-carbonyl bonding description. Relativistic effects on $\mathrm{Pt}$ make $r(\mathrm{PtC})$ in $\mathrm{PtCO}$ shorter than $r(\mathrm{PdC})$ in $\mathrm{PdCO}$. Experimental measurement of the distortion constants has yielded values consistent with those calculated from the harmonic force field of Manceron et al. ${ }^{7}$ A nuclear quadrupole coupling constant has been determined for ${ }^{105} \mathrm{Pd}$ in ${ }^{105} \mathrm{PdCO}$. Nuclear shielding parameters have been determined from the measured nuclear spin-rotation constant.

Acknowledgment. The research has been supported by the Natural Sciences and Engineering Research Council (NSERC) of Canada and by the Petroleum Research Fund, administered by the American Chemical Society.

\section{References and Notes}

(1) J. Mol. Catal. 2001, 173

(2) Molnár, A.; Sárhány, A.; Varga, M. J. Mol. Catal. A 2001, 173, 185.

(3) Manceron, L.; Tremblay, B.; Alikhani, M. E. J. Phys. Chem. A 2000, 104, 3750.

(4) Rohlfing, C. M.; Hay, J. P. J. Chem. Phys. 1985, 83, 4641. 3905 .
(6) Cheung, S. C.; Krüger, S.; Pacchioni, G.; Rösch, N. J. Chem. Phys. 1995, 102, 3695 .

(7) Tremblay, B.; Manceron, L. Chem. Phys. 1999, 250, 187.

(8) Pacchioni, G.; Kouteckỳ, J. J. Phys. Chem. 1987, 91, 2658.

(9) Blomberg, M. R. A.; Lebrilla, C. B.; Siegbahn, P. E. M. Chem. Phys. Lett. 1988, 150, 523.

(10) Smith, G. W.; Carter, E. A. J. Phys. Chem. A 1991, 95, 2327.

(11) Schwerdtfeger, P.; McFeaters, J. S.; Moore, J. F.; McPherson, D. M.; Cooney, R. P.; Bowmaker, G. A.; Dolg, M.; Andrae, D. Langmuir 1991, 7, 116.

(12) Pápai, A.; Goursot, A.; St-Amant, A.; Salahub, D. R. Theor. Chim. Acta 1992, 84, 217.

(13) Cheung, S. C.; Krüger, S.; Ruzankin, S. P.; Pacchioni, G.; Rösch, N. Chem. Phys. Lett. 1996, 248, 109.

(14) Kouteckỳ, J.; Pacchioni, G.; Fantucci, P. Chem. Phys. 1985, 99, 87

(15) Durà-Vilà, V.; Gale, J. D. J. Phys. Chem. B 2001, 105, 6158.

(16) Darling, J. H.; Ogden, J. S. J. Chem. Soc., Dalton Trans. 1973, 1079 .

(17) Evans, C. J.; Gerry, M. C. L. J. Chem. Phys. 2000, 112, 1321.

(18) Evans, C. J.; Gerry, M. C. L. J. Chem. Phys. 2000, 112, 9363.

(19) Evans, C. J.; Rubinoff, D. S.; Gerry, M. C. L. Phys. Chem. Chem. Phys. 2000, 2, 3943.

(20) Evans, C. J.; Lesarri, A.; Gerry, M. C. L. J. Am. Chem. Soc. 2000, 122,6100 .

(21) Walker, N. R.; Gerry, M. C. L. Inorg. Chem. 2001, 40, 6158.

(22) Evans, C. J.; Reynard, L. M.; Gerry, M. C. L. Inorg. Chem. 2001 , 40,6123 .

(23) Walker, N. R.; Gerry, M. C. L. Inorg. Chem. 2002, 41, 1236.

(24) Evans, C. J.; Gerry, M. C. L. J. Phys. Chem. A 2001, 105, 9659.

(25) Balle, T. J.; Flygare, W. H. Rev. Scient. Instrum. 1981, 52, 33. 206.

(26) Xu, Y.; Jäger, W.; Gerry, M. C. L. J. Mol. Spectrosc. 1992, 151,

(27) Brupbacher, T.; Bohn, R. K.; Jäger, W.; Gerry, M. C. L.; Pasinszki, T.; Westwood, N. P. C. J. Mol. Spectrosc. 1997, 181, 316.

(28) Walker, K. A.; Gerry, M. C. L. J. Mol. Spectrosc. 1997, 182, 178.

(29) Pickett, H. M. J. Mol. Spectrosc. 1991, 148, 371.

(30) Gordy, W.; Cook, R. L. Microwave Molecular Spectra: Techniques in Chemistry; Wiley: New York, 1984; Vol. XVIII.

(31) Rudolph, H. D. Struct. Chem. 1991, 2, 581.

(32) Costain, C. C. J. Chem. Phys. 1958, 29, 864.

(33) Watson, J. K. G.; Roytburg, A.; Ulrich, W. J. Mol. Spectrosc. 1999, 196, 102.

(34) Kuchitsu, K. J. Chem. Phys. 1968, 49, 4456.

(35) Kuchitsu, K.; Fukuyama, T.; Morino, Y. J. Mol. Spectrosc. 1969, 4,41

(36) Kuchitsu, K.; Morino, Y. Bull. Chem. Soc. Jpn. 1965, 38, 805

(37) Willner, H.; Bodenbinder, M.; Bröchter, R.; Hwang, G.; Rettig, S. J.; Trotter, J.; von Ahsen, B.; Westphal, U.; Jonas, V.; Thiel, W.; Aubke, F. J. Am. Chem. Soc. 2001, 123, 588.

(38) Jones, P. G. Z. Naturforsch. Teil B 1982, 37, 823.

(39) Kratzer, A. Z. Phys. 1920, 3, 289.

(40) Mills, I.; Cvitaš, T.; Homann, K.; Kallay, N.; Kuchitsu, K. Quantities, Units and Symbols in Physical Chemistry, 2nd ed.; Blackwell: Oxford, 1993.

(41) Flygare, W. H. J. Chem. Phys. 1964, 41, 793.

(42) Malli, G.; Fraga, A. Theor. Chim. Acta 1966, 5, 275.

(43) Wasylishen, R. E.; Bryce, D. L.; Evans, C. J.; Gerry, M. C. L. J. Mol. Spectrosc. 2000, 204, 184.

(44) Solupe, M.; Bauschlicher, C. W., Jr.; Lee, T. Chem. Phys. Lett. 1992, 189, 266.

(45) Kasai, Y.; Obi, K.; Ohshima, Y.; Endo, Y.; Kawaguchi, K. J. Chem. Phys. 1995, 103, 90.

(46) Hedberg, L.; Iijima, T.; Hedberg, K. J. Chem. Phys. 1979, 70, 3224.

(47) Beagley, B.; Cruickshank, D. W. J.; Pinder, P. M.; Robiette, A. G.; Sheldrick, G. M. Acta Crystallogr. 1969, B25, 737.

(48) Huber, K. P.; Herzberg, G. Molecular Spectra and Molecular Structure Constants of Diatomic Molecules; Van Nostrand: New York, 1979. 